\title{
One-year analysis of the iStent trabecular microbypass in secondary glaucoma
}

This article was published in the following Dove Press journal:

Clinical Ophthalmology

3 March 201I

Number of times this article has been viewed

\section{Oscar Buchacra \\ Susana Duch \\ Elena Milla \\ Oana Stirbu}

Department of Ophthalmology, Instituto Condal de Oftalmología, Barcelona, Spain
Correspondence: Susana Duch

Calatrava $10-12,5^{\circ} 2^{\circ}, 08017$

Barcelona, Spain

Tel +34 629370919

$\mathrm{Fax}+34932386581$

Email sduch@icoftalmologia.es
Purpose: To evaluate the midterm efficacy and safety of the iStent ${ }^{\circledR}$ glaucoma device in patients with secondary open-angle glaucoma.

Patients and methods: A prospective, nonrandomized, interventional case series involving 10 patients with secondary open-angle glaucoma (traumatic, steroid, pseudoexfoliative, and pigmentary glaucoma) of recent onset who underwent ab interno implantation iStent. Patients were assessed following the procedure on days 1, 7, and 15 and months 1, 3, 6, and 12, and examinations included visual acuity, intraocular pressure (IOP) measurement using Goldmann tonometry, number of glaucoma medications, and complications. Wilcoxon rank-test for data with abnormal distribution was used for the analysis of IOP and glaucoma medications at baseline versus 3, 6, and 12 months following the procedure.

Results: The mean baseline IOP was $26.5 \pm 7.9$ (range 18-40) $\mathrm{mmHg}$, and significantly decreased in $10.4 \pm 9.2 \mathrm{mmHg}$ at three months $(P<0.05)$, in $7.4 \pm 4.9 \mathrm{mmHg}$ at six months $(P<0.05)$, and in $6.6 \pm 5.4 \mathrm{mmHg}$ at 12 months $(P<0.05)$ following iStent implantation. The mean number of hypotensive medications at baseline was $2.9 \pm 0.7$ (range 2-4). Statistically significant reductions in the number of medications of $1.1 \pm 1.1$ were observed at three months $(P<0.05), 1.0 \pm 0.7$ at six months $(P<0.05)$, and $1.1 \pm 0.6$ at 12 months $(P<0.05)$. No significant changes in visual acuity were noted. The most common complications comprised mild hyphema in seven eyes and transient IOP $\geq 30 \mathrm{mmHg}$ in three eyes on postoperative day 1 . Obstruction of the lumen of the stent with a blood clot was seen in three eyes, and all instances resolved spontaneously.

Conclusion: The iStent is a safe and effective treatment option in patients with secondary openangle glaucoma, and reduces the topical treatment burden in one hypotensive medication.

Keywords: traumatic, steroid, pseudoexfoliative, pigmentary, stent

\section{Introduction}

In primary open-angle glaucoma, the site that offers greater resistance to outflow in the aqueous humor circulation is the juxtacanalicular meshwork. In the pseudoexfoliation syndrome, ${ }^{1,2}$ pigment dispersion syndrome, ${ }^{3,4}$ post-traumatic angle recession, ${ }^{5-7}$ or chronic treatment with steroids, ${ }^{8-10}$ this resistance may appear at different levels, such as pretrabecular or trabecular, leading to increased intraocular pressure (IOP) and thus to the optic neuropathy known as secondary open-angle glaucoma. Bypassing this point of greatest resistance would restore the outflow and regulate IOP.

The iStent $^{\circledR}$ (Glaukos Corporation, Laguna Hills, CA) is a new titanium device designed to be placed within Schlemm's canal, which connects directly to the anterior chamber. By means of bypassing the trabecular meshwork, this $60 \mu \mathrm{g}$ weight stent with 
a snorkel bore diameter of $120 \mu \mathrm{m}$ facilitates the outflow of aqueous humor into the collector channels that carry it to the episcleral veins. ${ }^{11}$ Recent studies have shown that in primary open-angle glaucoma, the iStent controls the physiologic flow of aqueous humor through the conventional route and restores the IOP. ${ }^{12,13}$

The effectiveness of this new device depends on the permeability of the post-trabecular system (Schlemm's canal and collector channels). Currently, there is no scanning technique available to assess the permeability of routes beyond the trabecular meshwork; therefore, we do not know a priori if implantation of a trabecular iStent is able to restore the aqueous humor drainage completely. However, clinically we have indirect signs of a well functioning post-trabecular system, such as blood reflux on gonioscopy with three-mirror lens. When the pretrabecular injury is de novo, we assume that the other angle structures are unaffected with proper function. Based on this hypothesis, all patients with ocular hypertension or newly diagnosed glaucoma and previously normotensive, who presented with increased IOP induced by trabecular mechanism, either due to pseudoexfoliation material, pigment dispersion, use of steroids, or secondary trabecular injury after angular recession, were assumed to have normal post-trabecular permeability and were potential candidates for this surgical procedure.

The aim of this study was to evaluate the safety and efficacy of the iStent in reducing IOP in patients with this type of secondary open-angle glaucoma.

\section{Material and methods}

This was a prospective, nonrandomized, noncomparative, interventional case series. All subjects were patients from the Glaucoma Department of the Instituto Condal de Oftalmologia, Barcelona. Prior to study enrollment, all participants provided informed consent to participate in the study which adhered to the tenets of the Declaration of Helsinki.

The study involved 10 eyes of 10 patients with secondary open-angle glaucoma (traumatic, pseudoexfoliative, steroid, or pigmentary glaucoma) of recent onset, ie, less than three months. Other inclusion criteria were an IOP $\geq 18 \mathrm{mmHg}$ (in at least two consecutive consultations) as suggested in previous studies, ${ }^{14-16}$ current use of at least one glaucoma medication, a visible scleral spur with gonioscopy, and readiness and willingness to attend follow-up visits for at least one year. We excluded any type of glaucoma other than the ones already mentioned. Other exclusion criteria were presence of angle closure, history of any glaucoma surgery or cyclodestructive procedure, elevated episcleral venous pressure, cloudy cornea or corneal opacities likely to prevent the surgeon from achieving a clear gonioscopic view of the nasal angle, or peripheral anterior synechiae in the nasal angle.

Data collected from each subject before surgery included age, gender, affected eye, type of secondary glaucoma, concurrent eye diseases, visual acuity, IOP, and number of hypotensive medications. Follow-up examination were performed on days 1,7 , and 15 and at months $1,3,6$, and 12 , and comprised visual acuity, slit lamp examination, gonioscopic evaluation of the location of the stent, IOP (Goldmann tonometry), number of hypotensive medications used, and complications.

No washout of hypotensive medications prior to surgery was required. Patients discontinued use of all glaucoma medications in the immediate postoperative period and were instructed to restart the treatment only if the investigator determined that additional lowering of IOP was needed.

\section{Surgical procedure}

The iStent is a L-shaped titanium trabecular stent. Its long arm has a sharpened end, which allows drilling of the trabecular meshwork into Schlemm's canal (intraluminal portion). The shorter arm remains located in the anterior chamber (extraluminal portion). All surgeries were performed by one of the authors (SD). Topical anesthesia with $1 \%$ hydrochloride tetracaine, and 4\% oxybuprocaine hydrochloride was used in all cases. After performing a $1.4 \mathrm{~mm}$ self-sealing temporal corneal incision, a viscoelastic agent ( $1 \%$ sodium hyaluronate) was injected to fill the anterior chamber. The nasal trabeculum was identified using a Swan-Jacobs gonioprism. Under gonioscopic view, the iStent attached at the end of a hand-piece applicator was introduced into the anterior chamber and positioned into the Schlemm's channel. While performing this maneuver, blood reflux was sometimes observed, indicating that the stent was correctly positioned. The stent was easily released by pressing the button on the applicator, and the viscoelastic agent was removed by manual aspiration. In the early postoperative period, a fixed combination of tobramycin and dexamethasone eye drops (Tobradex $^{\circledR}$, Alcon Inc, Fort Worth, TX) were administered three times daily for two weeks. Hypotensive agents were administered as needed.

\section{Statistical analysis}

Statistical analysis was performed with SPSS for Windows (SPSS Inc., Chicago, IL). Wilcoxon rank-test for data with abnormal distribution was used for the analysis of IOP and 
number of glaucoma medications before surgery versus months 3,6 , and 12 after surgery. A $P$ value less than 0.05 was considered statistically significant.

\section{Results}

Ten iStents were implanted between October 10, 2005 and March 5, 2007. Five patients underwent ocular surgeries prior to iStent implantation (Table 1). The mean age was 54.4 \pm 7.9 years and $90 \%$ were male. Four eyes were diagnosed with traumatic glaucoma, four eyes with steroid glaucoma, one eye with pigmentary glaucoma, and one eye with pseudoexfoliative glaucoma. Mean follow up was $12.7 \pm 4.6$ months. Of the 10 patients enrolled in the study, eight completed the 12-month follow-up. One patient was excluded from the study because IOP was not controlled with maximum medication at six months and consequently required trabeculectomy. The second patient was lost after the three-month visit when he returned to his country of origin.

The average pre-iStent IOP was $26.5 \pm 7.9$ (range 18-40) $\mathrm{mmHg}$, and the stent effectively decreased the IOP over the following 12 months (Table 2 and Figure 1). Statistical analysis was performed at months 3,6 , and 12 , taking into account the change in the number of patients, ie, $n=10$ at three months, $\mathrm{n}=9$ at six months, and $\mathrm{n}=8$ at 12 months. At all three time points, a decrease in mean IOP was observed, resulting in $17.0 \pm 2.5 \mathrm{mmHg}$ at 12 months (Table 3 ).

This reduction in IOP was statistically significant after iStent implantation at three months $(10.4 \pm 9.2 \mathrm{mmHg}, \mathrm{n}=10$, $P<0.05)$, at six months $(7.4 \pm 4.9 \mathrm{mmHg}, \mathrm{n}=9, P<0.05)$, and at 12 months $(6.6 \pm 5.4 \mathrm{mmHg}, \mathrm{n}=8, P<0.05)$. The proportion of patients that achieved an IOP $\leq 18 \mathrm{mmHg}$ was $70 \%(\mathrm{n}=7)$ at three months, $77.7 \%(\mathrm{n}=7)$ at six months, and $75 \%(n=6)$ at 12 months.

The average number of hypotensive medications preiStent was $2.9 \pm 0.7$ and ranged from two to four medications.
The mean number of hypotensive medications over time is illustrated in Figure 2. The study showed a significant reduction in the number of medications of $1.1 \pm 1.1(P<0.05)$ at three months, $1.0 \pm 0.7(P<0.05)$ at six months, and $1.1 \pm 0.6(P<0.05)$ at 12 months postoperatively.

After implantation of the iStent, an IOP of $\leq 18 \mathrm{mmHg}$ was achieved by $12.5 \%$ (1/8) without use of hypotensive medications and by $87.5 \%(7 / 8)$ with at least one medication. At 12 months, 25\% (2/8) needed at least two glaucoma medications.

Complications related to the surgical procedure included malposition of the iStent in one case that required a surgical repositioning which was successful. The most common postoperative complications were mild hyphema at 24 hours postprocedure ( $\mathrm{n}=7$ or $70 \%$ ), IOP $\geq 30 \mathrm{mmHg}$ on postoperative day 1 ( $n=4$ or $40 \%)$, that was medically controlled yet persisted in two eyes up to seven days, and corneal edema ( $n=2$ or $20 \%$ ) which resolved without sequelae. Obstruction of the lumen of the stent with a blood clot was seen in three eyes $(30 \%)$ which spontaneously resolved without the need for antifibrinolytic therapy. In this series of patients, there was no occlusion of the iStent due to the iris. In addition, no hypotony, choroidal detachment, temporary flattening of the anterior chamber, or endophthalmitis occurred. No significant changes were observed in visual acuity.

The patient who required trabeculectomy had had previous surgery for traumatic glaucoma with pars plana vitrectomy and phacoemulsification.

\section{Discussion}

In all types of secondary glaucoma (due to pseudoexfoliation, pigment, trauma, or steroids), obstruction and consequent increased resistance to outflow of aqueous humor through the conventional route cause increases IOP. We believe that in patients with de novo increased IOP, who previously have

Table I Demographics of the study population

\begin{tabular}{lllllll}
\hline Patient & Gender & Age & Eye & VA before surgery & Type of secondary glaucoma & Prior ocular surgery \\
\hline I & M & 43 & OD & $20 / 50$ & TG & PPV \\
2 & M & 47 & OS & $20 / 200$ & TG & - \\
3 & $M$ & 56 & OS & $20 / 200$ & TG & PPV, cataract surgery + IOL implantation \\
4 & M & 44 & OS & $20 / 200$ & SG & - \\
5 & F & 62 & OD & $20 / 40$ & SG \\
6 & M & 57 & OD & $20 / 25$ & SG & cataract surgery + IOL implantation \\
7 & M & 50 & OD & $20 / 25$ & PG & - \\
8 & M & 60 & OD & $20 / 20$ & SG \\
9 & M & 66 & OS & $20 / 20$ & PEXG & PKP \\
10 & M & 59 & OD & $20 / 800$ & TG & - \\
\hline
\end{tabular}

Abbreviations: F, female; M, male; OD, right eye; OS, left eye; PEXG, pseudoexfoliative glaucoma; PG, pigmentary glaucoma; PKP, penetrating keratoplasty; PPV, pars plana vitrectomy; SG, steroid glaucoma; TG, traumatic glaucoma; VA, visual acuity; IOL, intraocular lens. 
Table 2 Intraocular pressure over time by patient

\begin{tabular}{lllllllll}
\hline Patient & Before surgery & Day I & Day 7 & Day I5 & Month I & Month 3 & Month 6 & Month I2 \\
\hline 1 & 24 & 33 & 14 & 12 & 12 & 12 & 12 & 12 \\
2 & 36 & 8 & 26 & 13 & 8 & 12 & Lost to follow-up \\
3 & 40 & 8 & 19 & 12 & 22 & 20 & 28 & Trabeculectomy \\
4 & 30 & 12 & 13 & 36 & 18 & 19 & 18 & 20 \\
5 & 21 & 50 & 22 & 27 & 21 & 15 & 18 & 18 \\
6 & 30 & 52 & 16 & 22 & 22 & 18 & 18 & 17 \\
7 & 18 & 13 & 20 & 30 & 20 & 22 & 18 & 18 \\
8 & 30 & 10 & 18 & 18 & 15 & 10 & 21 & 19 \\
9 & 18 & 10 & 14 & 16 & 14 & 16 & 15 & 17 \\
10 & 18 & 10 & 12 & 10 & 22 & 17 & 14 & 15 \\
\hline
\end{tabular}

had normal IOP or recent history of glaucoma, the permeability of Schlemm's canal and collecting channels should be intact and function properly. Performing a bypass of the trabecular meshwork between the anterior chamber and Schlemm's canal and restoring the physiologic aqueous humor outflow might be an effective treatment option in this type of glaucoma. Because there are currently no available tools to evaluate the permeability of the conventional route, it is very important to assess slit lamp findings carefully, looking for indirect signs of blood reflux into Schlemm's canal using a goniolens or three mirror lens, as well as to take a thorough clinical history in order to determine the proper indication of iStent. Assuming that a well functioning iStent would increase the outflow of aqueous humor at the trabecular level, the percentage of IOP reduction would theoretically be higher in hypertensive than in normotensive eyes. ${ }^{13}$

The effectiveness of the iStent may depend on or be related to the permeability of the drainage system beyond Schlemm's canal. However, the long-term effectiveness of any device that bypasses the trabecular meshwork depends on scarring around the intraluminal portion of the iStent, which may be a limiting factor in aqueous humor flow through the stent. ${ }^{11}$ Theoretic models show that increased flow through the trabecular bypass would lead to an expansion of Schlemm's canal and collecting channels, which would further diminish the resistance to flow in eyes with glaucoma, from the anterior chamber into the aqueous veins. ${ }^{12}$

The existence of blockages at other levels beyond Schlemm's canal may be one of the causes of failure of this surgical procedure. Therefore, being able to predict the status of these drainage pathways is essential to prognosticate the future effectiveness of the iStent. Several studies have shown that, by bypassing the trabecular meshwork, the IOP decreases steadily in patients with chronic openangle glaucoma when the iStent is implanted concomitantly with phacoemulsification. Spiegel et al ${ }^{14,15}$ reported decreases in IOP of $25 \%(5.7 \pm 3.8 \mathrm{mmHg})$ in 47 patients with an initial IOP of $21.5 \pm 3.7 \mathrm{mmHg}$, and a reduction of $0.5 \pm 0.8$ in the number of hypotensive medications per day to six months. Samuelson et $\mathrm{al}^{16}$ described a decrease in IOP of $18.3 \%$ (4.4 $\mathrm{mmHg}$ ) with an initial IOP of $21.7 \mathrm{mmHg}$ at 12 months in 42 patients and a reduction in the number

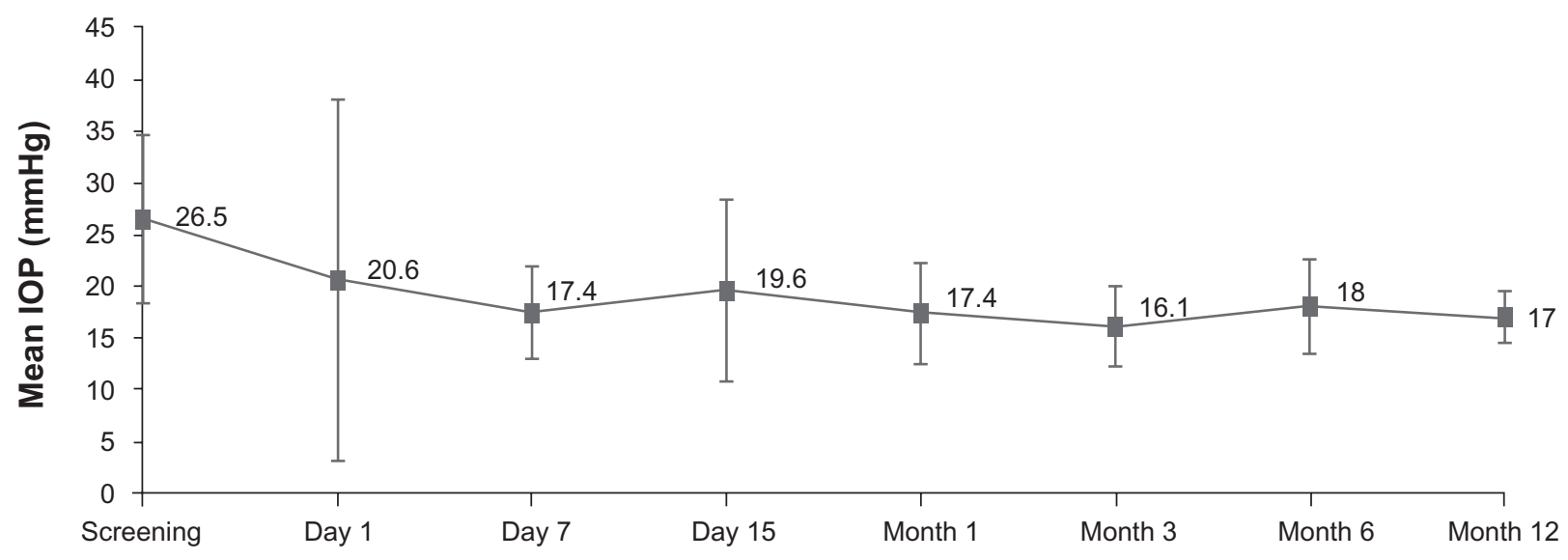

Figure I Mean IOP at each study visit. Abbreviation: IOP, intraocular pressure. 
Table 3 Mean intraocular pressure at baseline and months 3, 6, and I2

\begin{tabular}{lllll}
\hline Follow-up time & Patients $(\mathbf{n})$ & $\begin{array}{l}\text { Mean }( \pm \mathrm{SD}) \text { IOP } \\
\text { before surgery }\end{array}$ & $\begin{array}{l}\text { Mean }( \pm \mathrm{SD}) \text { IOP } \\
\text { after surgery }\end{array}$ & $\begin{array}{l}\boldsymbol{P} \text { value } \\
\text { (Wilcoxon rank-test) }\end{array}$ \\
\hline 3 months & 10 & $26.3 \pm 8.2$ & $16.1 \pm 3.9$ & 0.016 \\
6 months & 9 & $25.2 \pm 7.9$ & $18.0 \pm 4.6$ & 0.011 \\
12 months & 8 & $23.4 \pm 6.0$ & $17.0 \pm 2.5$ & 0.018 \\
\hline
\end{tabular}

Abbreviations: IOP, intraocular pressure; SD, standard deviation.

of medications per day of $1.2 \pm 0.7$. In a multicenter study, Samuelson et $\mathrm{al}^{17}$ compared the iStent with phacoemulsification versus phacoemulsification alone. Preoperative IOPs were $18.4 \pm 3.2$ with hypotensive medications, and $25.4 \pm 3.6$ without medications (after a washout period). They found a decrease of $>30 \%(8.4 \pm 3.6 \mathrm{mmHg}$ in the iStent with phacoemulsification group and $8.5 \pm 4.3 \mathrm{mmHg}$ in the phacoemulsification alone group). They also found a reduction in the number of medications of $1.4 \pm 0.8$ in the iStent with phacoemulsification group and $1.0 \pm 0.8$ in the phacoemulsification alone group.

In our series of patients with secondary open-angle glaucoma, iStent insertion achieved IOP reductions of $28.6 \%$ $(7.4 \pm 4.9 \mathrm{mmHg})$ at six months in nine patients and $27.3 \%$ $(6.6 \pm 5.4 \mathrm{mmHg})$ at 12 months in eight patients without associated cataract surgery. These percentage values of IOP lowering are superior to those reported in previous studies ${ }^{14-16}$ and are similar to the multicenter study of Samuelson et $\mathrm{al}^{17}$ where they compared preoperative IOP without medications. This is probably due to the fact that pretreatment IOP values were greater in our series, with similar absolute values of lowering compared with the other studies mentioned earlier, taking into account that the preoperative IOP was with hypotensive medications. This finding supports the hypothesis that the success of the iStent is greater with increased preoperative IOP. ${ }^{13}$
The reduction in the number of hypotensive medications in our series was $1.0 \pm 0.7$ at six months and $1.3 \pm 0.6$ at 12 months, which are values similar to the series published by Samuelson et $\mathrm{a}^{16,17}$ and higher than in the study conducted by Spiegel et al. ${ }^{15}$

Our study shows that the insertion of iStent is a safe procedure that does not have any of the more common complications of filtering surgery. Furthermore, the conjunctiva remains intact, so that if a filtering procedure is needed later, the success rate should not be affected. The decrease in the number of medications is a positive factor to consider, because we have found that the implantation of one iStent reduces the topical treatment burden in one medication, making this type of surgery a good option in patients with intolerance to glaucoma eye drops. If we seek a greater reduction in the IOP, we should consider the implantation of more than one device.

For patients with pigmentary glaucoma or pseudoexfoliation, we do not know if there is a direct passage of pigmentary material into Schlemm's canal and collecting ducts. This consideration should be evaluated in future pathologic studies. The small number of patients is a limitation of our study, so larger and longer-term studies are needed to confirm these results in patients with secondary open-angle glaucoma, considering also the placement of more than one iStent.

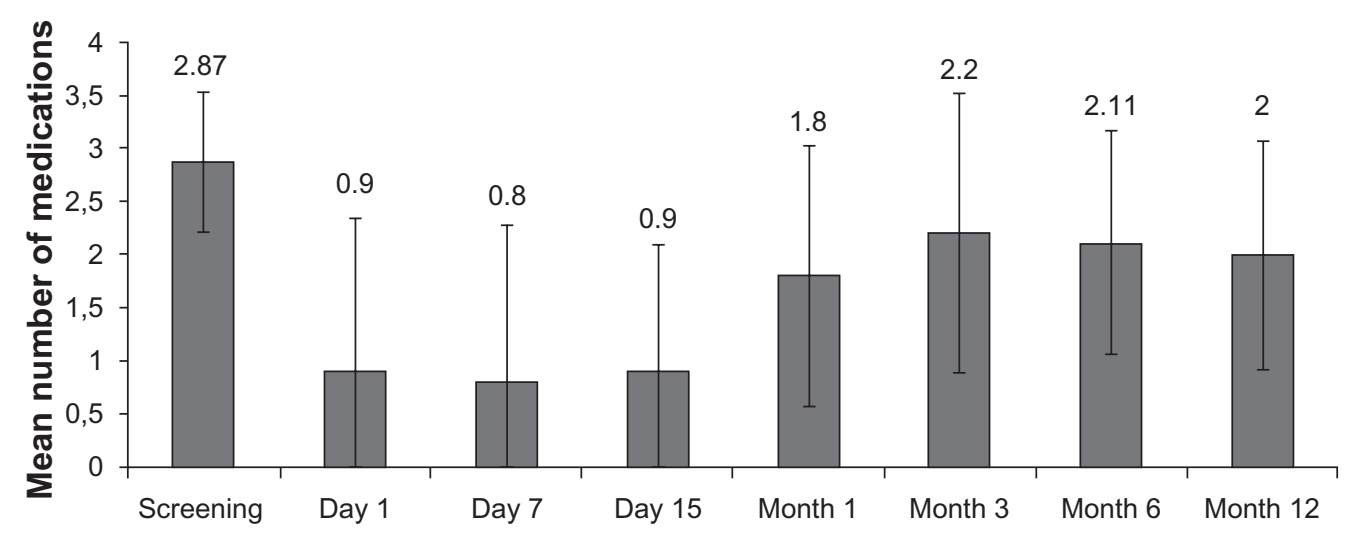

Figure $\mathbf{2}$ Mean number of hypotensive medications used at each study visit. 
Presently, widespread use of intraocular triamcinolone for macular pathology has led to a substantial increase in the incidence of steroid ocular hypertension, which sometimes cannot be managed with topical treatment. In these cases, an iStent might achieve prompt control of IOP with minimal invasive risk, and be extremely convenient and suitable for patients with retinal pathology.

\section{Conclusion}

This study shows that iStent implantation without concomitant cataract surgery is a safe treatment option in patients with secondary open-angle glaucoma. The procedure is also effective because it achieves IOP reduction depending on the initial pressure and decreases the burden of topical glaucoma medication.

\section{Acknowledgment}

We thank Fernando Sanchez and Cristina Hernandez, Instituto Condal de Oftalmologia, for their help in recording patient data and providing photographs.

\section{Disclosure}

The authors report no conflicts of interest in this work.

\section{References}

1. Stefan C, Tebeanu E, Nenciu A. Pseudoexfoliative glaucoma. Oftalmologia. Romanian. 2007;51:50-52.

2. Gottanka J, Flugel-Koch C, Martus P, Johnson DH, Lutjen-Drecoll E. Correlation of pseudoexfoliative material and optic nerve damage in pseudoexfoliation syndrome. Invest Ophthalmol Vis Sci. 1997; 38:2435-2446.

3. Campbell DG. Pigmentary dispersion and glaucoma: A new theory. Arch Ophthalmol. 1979;97:1667-1672.
4. Gottanka J, Johnson DH, Grehn F, Lütjen-Drecoll E. Histologic findings in pigment dispersion syndrome and pigmentary glaucoma. J Glaucoma. 2006;15:142-151.

5. Manners T, Salmon JF, Barron A, Willies C, Murray ADN. Trabeculectomy with mitomycin $\mathrm{C}$ in the treatment of post-traumatic angle recession glaucoma. Br J Ophthalmol. 2001;85:159-163.

6. Canavan YM, Archer DB. Anterior segment consequences of blunt ocular injury. Br J Ophthalmol. 1982;66:549-555.

7. De La Cámara J, Seffino E. Glaucoma por recesión angular. Arch Soc Esp Oftal. 1977;37:37-52. Spanish.

8. Weinreb RN, Bloom E, Baxter JD, et al. Detection of glucocorticoid receptors in cultured human trabecular cells. Invest Ophthalmol Vis Sci. 1981;21:403-407.

9. Wilson K, McCartney MD, Miggans ST, Clark AF. Dexamethasone induced ultrastructural changes in cultured human trabecular meshwork cells. Curr Eye Res. 1993;12:783-793.

10. Samples JR, Alexander JP, Fisk A, Acott TS. Regulation of the levels of human trabecular matrix metalloproteinases and inhibitor by interleukin-1 and dexamethasone. Invest Ophthalmol Vis Sci. 1993;34:3386-3395.

11. Bahler CK, Smedley GT, Zhou J, Johnson DH. Trabecular bypass stents decrease intraocular pressure in cultured human anterior segments. Am J Ophthalmol. 2004;138:988-994.

12. Zhou J, Smedley GT. Trabecular bypass: Effect of Schlemm canal and collection channel dilation. J Glaucoma. 2006;15:446-455.

13. Zhou J, Smedley GT. A trabecular bypass flow hypothesis. J Glaucoma. 2005; 14:74-83.

14. Spiegel D, Wetzel W, Stürmer J, et al. Co-existent open-angle glaucoma and cataract: Treatment by cataract surgery and the i-Stent trabecular bypass micro stent. Poster presented at the Annual Meeting of the Association of Research in Vision and Ophthalmology, 2005 May 1-5, Fort Lauderdale, FL.

15. Spiegel D, García-Feijoó J, García-Sanchez J, Lamielle H. Coexistent primary open-angle glaucoma and cataract: Preliminary analysis of treatment by cataract surgery and the iStent trabecular micro-bypass stent. Adv Ther. 2008;25:453-464.

16. Samuelson TW, Katz J. 12-month analysis of the i-Stent trabecular micro-bypass and concurrent cataract surgery. Poster presented at the American Glaucoma Society Annual Meeting, 2007 Mar 1-4, San Francisco, CA.

17. Samuelson TW, Katz LJ, Wells JM, Duh YJ, Giamporcaro JE; US iStent Study Group. Randomized evaluation of the trabecular micro-bypass stent with phacoemulsification in patients with glaucoma and cataract. Ophthalmology. 2010 Sep 8. [Epub ahead of print].
Clinical Ophthalmology

\section{Publish your work in this journal}

Clinical Ophthalmology is an international, peer-reviewed journal covering all subspecialties within ophthalmology. Key topics include: Optometry; Visual science; Pharmacology and drug therapy in eye diseases; Basic Sciences; Primary and Secondary eye care; Patient Safety and Quality of Care Improvements. This journal is indexed on Submit your manuscript here: http://www.dovepress.com/clinical-ophthalmology-journal

\section{Dovepress}

PubMed Central and CAS, and is the official journal of The Society of Clinical Ophthalmology (SCO). The manuscript management system is completely online and includes a very quick and fair peer-review system, which is all easy to use. Visit http://www.dovepress.com/ testimonials.php to read real quotes from published authors. 